\title{
Cellulose Nanocrystal-based Liquid Crystal Structures and the Unique Optical Characteristics of Cellulose Nanocrystal Films
}

Xiaoyao Wei, Tao Lin, Min Duan, Hengli Du, and Xuefeng Yin*

Liquid crystals (LC) have been found to have many unique characteristics during the last few decades. The liquid crystal phase is ubiquitous in the biological world, as well as in cellulose and its derivatives. Cellulose nanocrystals (CNC), which can obtain the chiral LC phase in aqueous suspension, have been attracting much attention. The unique size and properties of CNC, such as their light weight, special optical properties, non-toxicity, and biocompatibility, etc., have made them widely applicable in diverse fields. This brief literature review introduces the relationship between the LC phase and CNC. Advantages of CNC as a liquid crystal forming material and the preparation of CNC are discussed. The left-handed cholesteric phase structure and the corresponding unique optical properties of CNC-based LC are described in detail. The CNC-based LC aqueous suspension and three stages of forming LC phase are also described. Then, the main reasons accounting for the brittleness and non-uniformity of pristine CNC-based LC are summarized, as well as ways to overcome these problems. Finally, some optical applications of CNC-based LC films in anticounterfeiting, colorimetric sensors, and composite devices are considered.

Keywords: Liquid crystals; Cellulose nanocrystals; Left-handed cholesteric; Optical properties; CNC-based LC; Non-uniformity

Contact information: College of Bioresources Chemical and Materials Engineering, Shaanxi Province Key Laboratory of Papermaking Technology and Specialty Paper, National Demonstration Center for Experimental Light Chemistry Engineering Education, Shaanxi University of Science and Technology, Xi'an 710021, Shaanxi, P. R. China; *Corresponding author: yinxuefeng@sust.edu.cn

\section{INTRODUCTION}

Liquid crystals (LC) signify a state that is intermediate between that of a crystalline solid and an amorphous liquid, so it can also be regarded as a mesophase. They exhibit some degree of isotropy like a liquid. At the same time then can retain the order of a crystal, at least in one direction, such that the anisometric molecules possess only orientational order and no positional order (Collings 1990, 1998) (Fig. 1). The LC assembly behavior results in corresponding optical properties (Mitov 2017), and they show chiral or achiral structure in nature (Oswald and Pieranski 2005; Mathews et al. 2010; Li et al. 2013a,b; Takezoe and Eremin 2017; Zheng et al. 2017). Those characteristics have been considered as a compelling discipline in the research on LC and also have received increased attention in recent years. Many polymers in daily life exhibit a LC phase. Examples include DNA, RNA, viruses, stratum corneum, the beetle, etc. (Zhou and Wang 1994), but the natural structure of LC systems from different sources are not exactly the same. Most derivatives of cellulose easily form LC phases in polar

Wei et al. (2021). "CNC-based liquid crystals structure," BioResources 16(1), 2116-2137. 2116 
solvents such as water, ethanol, and dimethyl sulfoxide (DMSO) (Grunert and Winter 2002; Viet et al. 2007; Okura et al. 2014). This paper mainly focuses on the CNC-based LCs, because they possess many unique advantages such as high aspect ratio, large specific surface area, high crystallinity, good mechanical properties, special optical effect, and notable self-assembly performance compared to others.

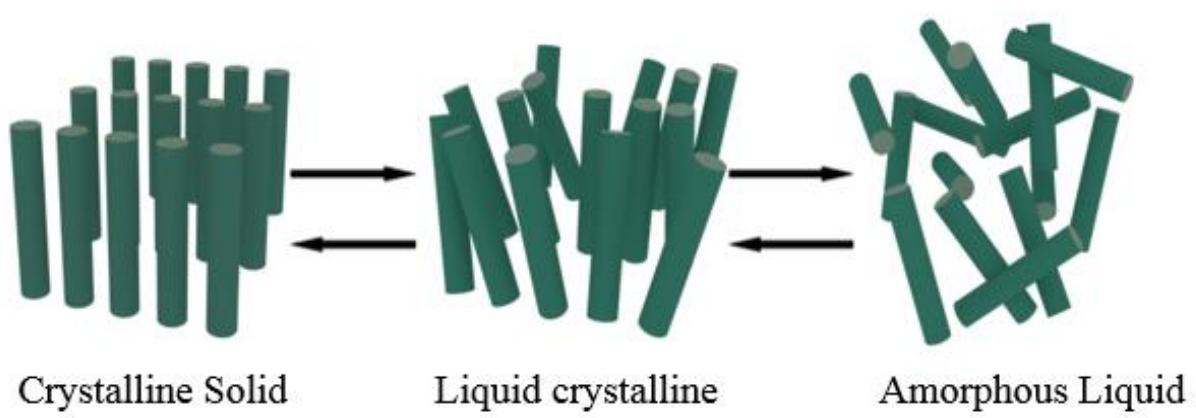

Fig. 1. Arrangement of rod-like particulars of liquid crystalline phase with liquid and crystalline solid

Cellulose is one of the most widely used and abundant polymers in nature. The worldwide production of this biopolymer exceeds 75 billion tons each year (Habibi et al. 2010). Cellulosic materials with diameters in the nanometer range are defined as nanocellulose. According to different cellulose sources and route methods, various forms of nanocellulose can be produced; the main types are cellulose nanofibers (CNF), cellulose nanocrystals (CNC), and bacterial nanocellulose (BNC) (Eichhorn et al. 2010; Klemm et al. 2011; Moon et al. 2011). The property differences of these three types are mainly dependent upon inherent crystallinity, morphology, and size. CNF and BNC prefer to form gels in aqueous suspensions before developing long-range order, so they are little used in the field of synthetic LC materials. CNC can form a lyotropic LC suspension in a suitable solvent. A lyotropic LC is a kind of LC formed by two or more compounds including solvent compounds, and when the concentration of solute molecules is within a certain range, liquid crystal phase will appear. So a CNC aqueous suspension will trigger the start of kinetics of self-assembly to a cholesteric LC phase at a critical concentration. The unique structure of a CNC-based LC suspension will produce optical characteristics, and it can further form films that retain distinctive optical character. In recent years, more and more attention has been paid to the application of CNC-based LC films, but there are still many unknowns in this process. Therefore, it is very important and necessary to study the structure and film formation of CNC-based LC in detail.

This mini-review differs from other reviews of the topic in that it systematically introduces the information from liquid crystal to CNC, CNC LC aqueous suspensions, CNC-based LC film formation, and film application. First to be introduced is the structure of $\mathrm{CNC}$, along with the arrangement and the kinetics of CNC-based LCs. The structural and optical properties of CNC-based LC films from CNC to CNC aqueous suspension are shown. Then, two defects of CNC-based LC film are introduced: brittleness and non-uniformity. The causes of these defects, as well as control methods, are explained according to the latest structural studies. Although research on $\mathrm{CNC}$ films is not as extensive as research on CNC aqueous suspensions, the application of optical

Wei et al. (2021). "CNC-based liquid crystals structure," BioResources 16(1), 2116-2137. 2117 
film has aroused many people's interest. Therefore, the main applications of CNC-based LC films in recent years are summarized, mainly optical anti-counterfeiting, sensors about the optical color change and some composite devices.

\section{STRUCTURE OF CNC-BASED LIQUID CRYSTALS}

\section{Structure and Preparation of CNC}

$\mathrm{CNC}$ has a typical rod-like shape that is nanometers in diameter and can be isolated from plants and other biological sources (Revol et al. 1992; Lima and Borsali 2004; Bondeson et al. 2006; Habibi et al. 2010; Brinchi et al. 2013). It is composed of linear chains that contain hundreds to thousands of sugar units (cellobiose units). The cellobiose unit is a disaccharide of two glucose molecules linked together through a $\beta(1$ 4) glycosidic bond (Moon et al. 2011; Klemm et al. 2018; Ling et al. 2018) (Fig. 2). In addition to the native crystalline allomorph of cellulose I, there are different allomorphs cellulose II (Flauzino Neto et al. 2016; Sèbe et al. 2012; Gong et al. 2017, 2018; Kuang et al. 2020), cellulose III, and cellulose IV (Ishikawa et al. 1997; Gong et al. 2018; González-Domínguez et al. 2019; Wu et al. 2020). At present, although there are many routes and raw materials for $\mathrm{CNC}$ production, industrial $\mathrm{CNC}$ is composed of cellulose I (CNC-I). CNC-II, III, and IV can be obtained by different chemical treatments of cellulose I. Compared with $\mathrm{CNC}$-III and IV, CNC-II has more research about morphology, but it is far less studied than CNC-I. Delepierre et al. (2020) pointed out that CNC-I and II obtained by sulfuric acid hydrolysis show similar surface charge density and potential, and both have right-handed distortion, but they show very different LC behaviors. The concentrated CNC-I was formed into a cholesteric phase with small spacing in a short time, but CNC-II was first divided into an upper isotropic phase and a lower nematic LC phase, and then it finally formed cholesteric phase with large spacing in a long time. This review focuses on the most widely used and researched CNC-I, which for convenience, will be written as CNC.

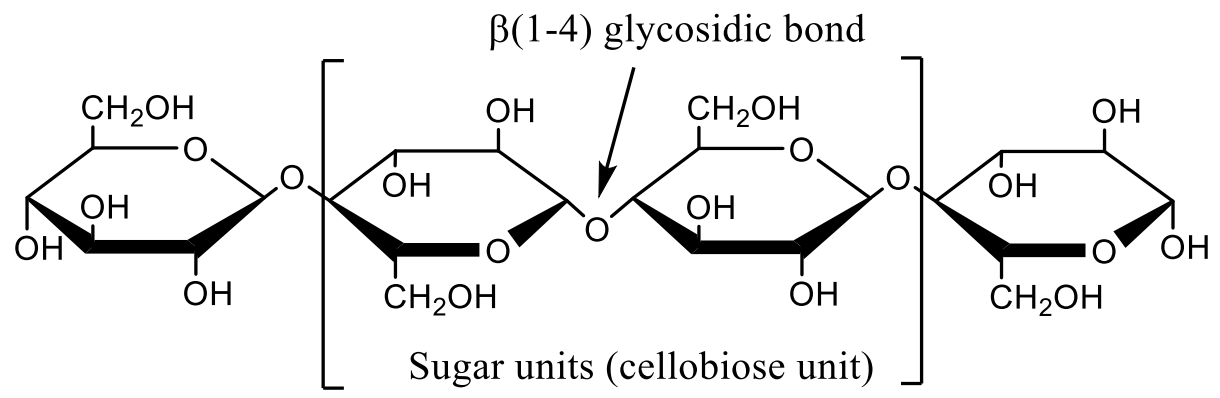

Fig. 2. The basic unit structure of cellulose

The size of CNC can range from $100 \mathrm{~nm}$ to several micrometers in length and 4 to $70 \mathrm{~nm}$ in width, wherein the difference depends on the source of cellulose fibers and the preparation method (Singla et al. 2016; Jonoobi et al. 2015). As natural cellulose is composed of both crystalline regions and more readily hydrolyzable amorphous regions, which will easily cleaved and destroyed by strong acids such as sulphuric acid, CNC can be produced after removing the amorphous regions (Trache et al. 2017). Through esterification of hydroxyl groups by sulphate ions (sulfuric acid is the most common 
hydrolyzing agent), the negatively sulfate ester groups at CNC surface will be produced. As a top-down approach (Capron et al. 2017), sulfuric acid hydrolysis is the most popular and important method for CNC production (Gilbert 1994; Samir et al. 2004a). Other mild acids, such as formic acid, acetic acid, phosphoric acid, chlorine oxide, etc., can also be used as a hydrolyzing agent to alter the reaction parameters (Samir et al. 2004a). The CNC obtained by acid hydrolysis in different raw materials, such as cotton (Revol et al. 1994; Podsiadlo et al. 2005), wood (Revol et al. 1992; Beck-Candanedo et al. 2005; Bondeson et al. 2006), tunicate (Favier et al. 1995; Samir et al. 2004b), etc., have different sizes with lengths ranging from 100 to $2000 \mathrm{~nm}$ and diameters ranging from 2 to $50 \mathrm{~nm}$. In recent years, mechanical treatment (Amin et al. 2015), oxidation method (Saito et al. 2006; Qin et al. 2011; Cao et al. 2012), enzymatic hydrolysis (Satyamurthy et al. 2011; Chen et al. 2012), and some novel CNC preparation methods have been reported. Mao et al. (2013) used an ionic solution ([BMIM]HSO 4$)$ to treat microcrystalline cellulose (MCC), and finally prepared $\mathrm{CNC}$ with a yield of $48 \%$. Later, through the optimization of this method, CNC obtained a yield of $57.7 \%, 57.0 \%$, and $75.6 \%$ from coniferous wood, hardwood, and MCC, respectively (Mao et al. 2013). Sirviö et al. (2016) found that a deep eutectic solvent (DES) system (choline chloride/oxalic) combined with mechanical treatment can get the small length-diameter ratio and good dispersibility of CNC colloidal aqueous suspension, with a yield over $70 \%$ and a carboxyl content on the surface of 0.20 to $0.27 \mathrm{mmol} / \mathrm{g}$ (Sirviö et al. 2016; Laitinen et al. 2017).

\section{Theoretical Structure and Optical Properties of CNC-based Liquid Crystals}

The structural trait of CNC-based LCs was first discovered by Revol et al. (1992).

This structural trait allows CNC to be easily be dispersed in water so that it can spontaneously self-organize into a cholesteric LC phase at quite a low mass fraction (Revol et al. 1998; Edgar and Gray 2011). In the CNC-based LC structure, nanoparticles are arranged by layers ( $x y$-plane). The orientation of the long axis (helix axis $\mathrm{m}$ ) of the layer is same, but the positions of the axes (director $n$ ) are different. When the helix axis $\mathrm{m}$ is along the $\bar{z}$-axis, the director $\mathrm{n}$ will be rotated to the left by a certain angle layer-bylayer, which makes the whole structure spiral (Werbowyj and Gray 1984; Schütz et al. 2020). When director $n$ is rotated 360 degrees, the distance between the layers is called the helical pitch (Fleming et al. 2001; Pan et al. 2010), often referred to as $P$. Generally, the $P$ value ranges from a hundred nanometers to several micrometers and is controlled mainly by the nanocrystal concentration, geometry, electrostatic charge and external conditions such as magnetic field, polymer and so on (Hiraia et al. 2009; Pan et al. 2010; Espinosa et al. 2013; Chen et al. 2020; Bardet et al. 2014).

A cholesteric phase is a kind of nematic phase in which the nanoparticle structure of the nematic phase is chiral (Kitzerow and Bahr 2001; Ingo and Shakhawan 2017). The chiral structure along its helix axis has a strong optical activity. This helical structure of CNC suspension exhibits strong birefringence (Giese et al. 2015; Almeida et al. 2018; Parker et al. 2018; Huang et al. 2019) and templating potentials (Giese et al. 2015; Levin et al. 2018; Parker et al. 2018) can been maintained in dried CNC films. The value of $P$ determines the wavelength of the reflected light that results in the color transition (Werbowyj and Gray 1984), the phenomenon that Dumanli et al. (2014) also certified on a CNC-based LC film. The wavelength of the reflected light is described by the Bragg (Vries 1951) equation, given as Eq. 1,

$$
\lambda=n P \sin \theta
$$

Wei et al. (2021). "CNC-based liquid crystals structure," BioResources 16(1), 2116-2137. 2119 
where $\lambda$ is the reflected wavelength, $P$ is the helical pitch, $\theta$ is the angle $\left(^{\circ}\right)$ of the incident light, $\sin \theta=1$ when the incident light is perpendicular to the crystal plane, and $n$ is the average refractive index of the material (Lagerwall 2013; Nguyen et al. 2018) (Fig. 3). Thus, the colorful images below obtained by polarized optical microscopy (POM) could provide reliable evidence about the cholesteric LC (Tran et al. 2020).

(a)

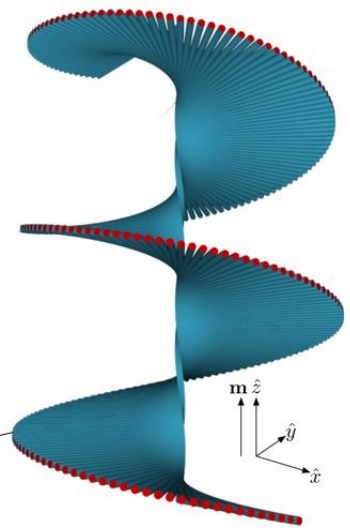

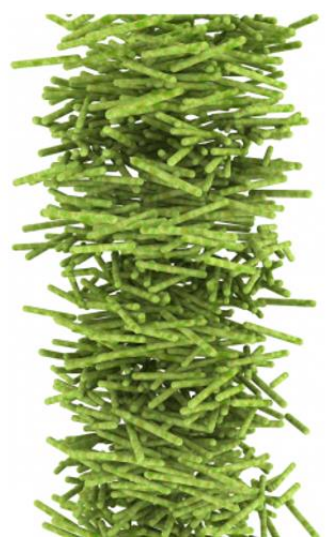

(b)

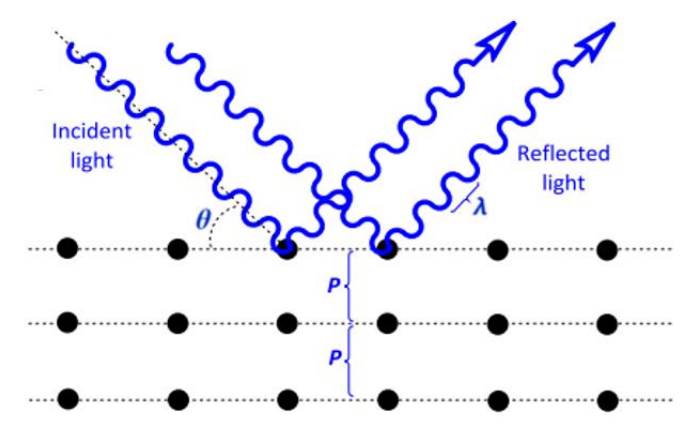

Fig. 3. Scheme (a) showing the left-handed cholesteric structure of CNC, (b) the reflected light with helical pitch $P$ and incident light angle $\theta$; Fig. 3(a) reproduced with permission from Crystals and Fig. 3(b) @ European Physical Society. Reproduced by permission of IOP Publishing. All rights reserved.

\section{Formation Process of CNC-based Liquid Crystals}

According to Onsager's theory, the nematic ordering of rod-like CNC is based on the balance of translational entropy and orientational entropy. In order to better understand that nematic ordering is caused by entropic contributions, Schütz et al. (2020) used "excluding volume" for reinterpretation: the space is not accessible for a rod due to the presence of other rods. This limits the freedom of motion and reduces orientational entropy, but by arranging themselves along a common direction, the total excluded volume is minimized, and the translation freedom is improved, thus increasing translational entropy and reducing free energy. In addition, due to electrostatic repulsion, a CNC aqueous suspension can show good stability against agglomeration, which is conducive to the generation of the LC phase. Zhong et al. (2012) studied the influence of electrolyte composition and $\mathrm{pH}$ value on stability of $\mathrm{CNC}$ suspensions in detail. Increasing the concentration of inorganic cations $\left(\mathrm{Na}^{+}\right.$and $\left.\mathrm{Ca}^{2+}\right)$ will lead to aggregation of $\mathrm{CNC}$, and the divalent ion $\mathrm{Ca}^{2+}$ has more influence on stability of CNC suspension. The organic low-molecular-weight electrolyte sodium dodecyl sulfate (SDS) is beneficial to the stability of CNC suspension, while organic high-molecular-weight electrolyte sodium carboxymethyl cellulose (CMC) can induce aggregation of CNC particles. Under low ionic strength $\left(\mathrm{Na}^{+}, 1 \mathrm{mM}\right), \mathrm{CNC}$ is stable in aqueous suspension with $\mathrm{pH}$ of 2 to 11 .

The cholesteric phase will be triggered when the well-dispersed CNC is beyond a critical concentration in the solution. The suspension at the critical concentration will be at an equilibrium conformation, but the suspension no longer contains its equilibrium state as an increased amount of water is removed (Revol et al. 1992). The CNC aqueous suspension self-organizing process is divided into three stages (Gray 2016) (Fig. 4). Figure 6A shows the first stage, in which the suspension is in the isotropic phase and does not appear to self-organize. Thus, the suspension in this stage is shown in the black image by polarized optical microscope.

Wei et al. (2021). "CNC-based liquid crystals structure," BioResources 16(1), 2116-2137. 2120 
(a)

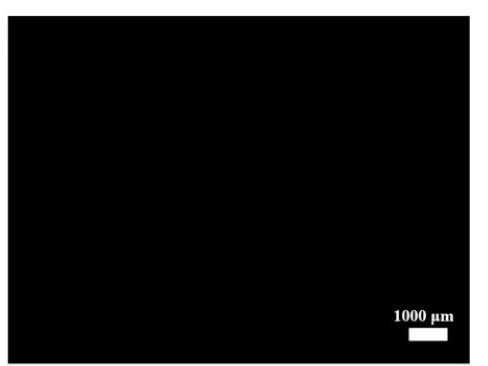

The first stage

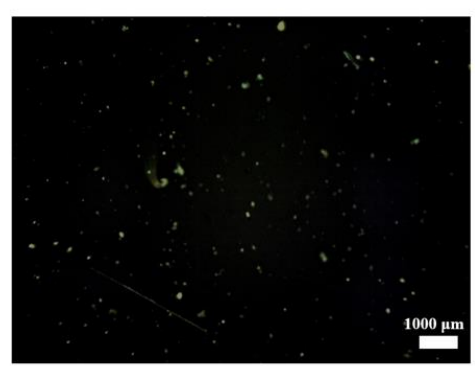

The second stage

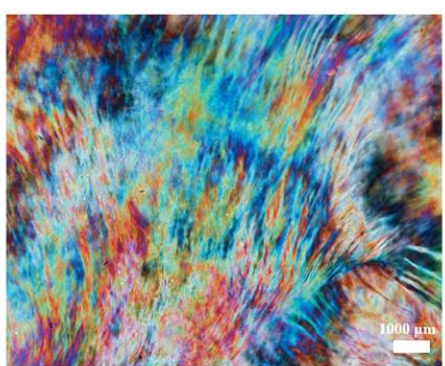

The third stage

(b)

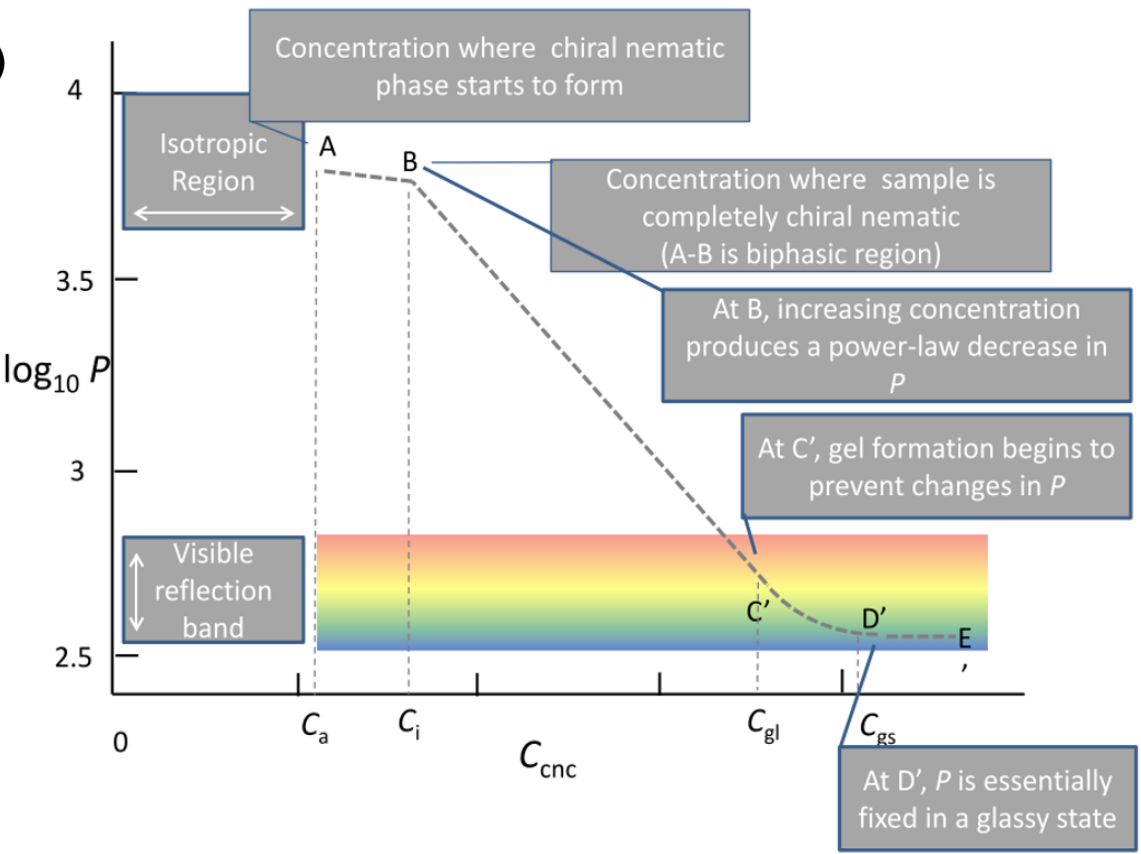

Fig. 4. (a) Self-organization process stage of CNC aqueous suspension with POM image; (b) relationship about CNC concentration, $P$, and reflection; Fig. 4(b) reproduced with permission from Nanomaterials

Figures 6A and 6B show the second stage. The critical value of $C_{\mathrm{a}}$ is the concentration where the chiral nematic phase starts to form (Zhang et al. 2017), the CNC aqueous suspension spontaneously produces the anisotropic phase while in the existing isotropic phase, so it is called the biphasic region. These spherical or elliptical anisotropic phases are called tactoids (Sonin 1998), a term originally proposed by Zocher and Jacobsohn (1929). They can be dispersed in isotropic liquid and display partial color images under a polarizing microscope. The third stage is shown after Fig. 6B. Once the CNC aqueous suspension concentration passes the $C_{\mathrm{i}}$, the suspension transitions to a kinetic arrest state. That means that no further helical organization can occur and tactoids will fuse with each other to form a continuous anisotropic phase, namely a cholesteric LC phase (Tjipto-Margo and Evans 1991; Moon et al. 2011). The third stage has colorful images in the entire area by polarized optical microscope. Therefore, the colorful POM image can indicate the state of $\mathrm{CNC}$ aqueous suspension under phase transitions.

When the incident light angle $\theta$ is invariant, the reflected light wavelength relies on the $P$ value. The rainbow area is the visible reflection band that represents the range of $P$ values that reflect visible light. Figure $6 \mathrm{~B}$ shows the third stage, where increasing 
concentration produces a power-law decrease in $P$, but in the $\mathrm{C}^{\prime}-\mathrm{D}^{\prime}$, gel formation begins to prevent change in $P$, and after $\mathrm{D}^{\prime}, P$ is essentially fixed in a glass state. The $C_{\mathrm{gl}}$ and $C_{\mathrm{gs}}$ are the concentrations for gel and solid glass formation, respectively.

\section{CNC-BASED LIQUID CRYSTAL FILMS}

\section{Pristine Film of CNC-based Liquid Crystals}

The microscopic topography of CNC in aqueous suspension is shown to be uniformly dispersed at low concentration during the drying process (Figs. 5a, b). The CNC suspension with high concentration was set in a kinetic state of arrest, which preserved the cholesteric helical order in the course of generation of the solid film (Edgar and Gray 2011). The kinetic arrest fixes the pitch $P$ and locks the cholesteric order in its original position. With the evaporation of the aqueous solution, the $\mathrm{CNC}$ fraction is increased to $100 \mathrm{wt} \%$ (Liu et al. 2014).

The color of the films is produced by the wavelength of reflected light, which depends on the helical $P$ and the angle of incident light. When the incident light wavelength is in the visible range, the material appears colorful to the naked eye (Lima and Borsali 2004; Beck et al. 2011). The CNC-based cholesteric LCs have the selective reflection phenomenon for the entrance of circularly polarized light, and for the lefthanded axis of helical structure, the left-circularly polarized (LCP) light will be completed reflected and right-circularly polarized (RCP) light will pass through the CLC material (Kitzerow and Bahr 2001; Nishio et al. 2016). Thus, the polarization of reflected light provides reliable evidence about the chiral order of colorful CNC-based LC films (Kelly et al. 2014). Normally, the color of such films is blue under the incidence of natural light (Vignolini et al. 2012). The pristine CNC-based LC film tends to be brittle (Gray 2016) and is non-uniform in structure, which limits the application range of the CNC-based LC film. For a perfectly uniform planar film, the nanoparticle layer is parallel to the film surface and the axis of the helicoid is perpendicular to the film surface, so a cross-section through the film normal to the surfaces shows a periodic layered structure (Fig. 5c). 

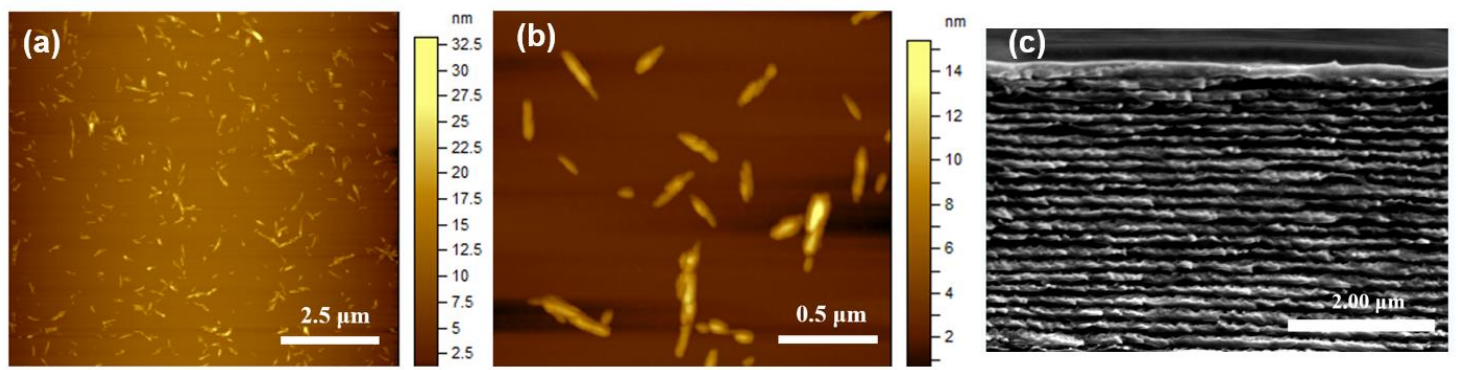

Fig. 5. Microscopic topography of CNC (a) and (b) AFM image of same CNC aqueous suspension sample in $2.5 \mu \mathrm{m}$ and $0.5 \mu \mathrm{m}$, respectively, (c) A scanning electron microscope image of cross-section of the CNC-based LC film

The brittleness of CNC-based LC films is due to the fact that CNC particles are rigid, so they can't relieve external stresses by deformation, and there is no connection between CNC rods except hydrogen bonds; consequently cracks will easily form (Singh et al. 2009; Edgar and Gray 2011; Passantino et al. 2017). The CNC-based LC films tend to be nonuniform, mainly for two reasons. The first is that there are randomly arranged directions of helix and various $P$ values in the whole film, which finally causes the helix axes to be oriented at an angle to the surface in the dried film. In the process of drying, the film exhibits many tactoids with cholesteric and well organized structure that can be observed by scanning electron microscope (Wang et al. 2016). As shown in Fig. 6, the helix axis directions of these tactoids are not exactly the same, and the sizes of tactoids are also different. When these tactoids are gradually merged and deposited, they form layered chiral nematic phase structures. In addition, after the kinetic arrest during the drying suspension, with the evaporation of solvent, tactoids will be compressed vertically, resulting in further distortion of the helix axis (Frka-Petesic et al. 2019). The second reason is a macroscopic non-homogeneity phenomenon-coffee ring effect. This is an obvious ring-shaped deposits phenomenon, which was first explained by Deegan et al. (1997) (Fig. 7).

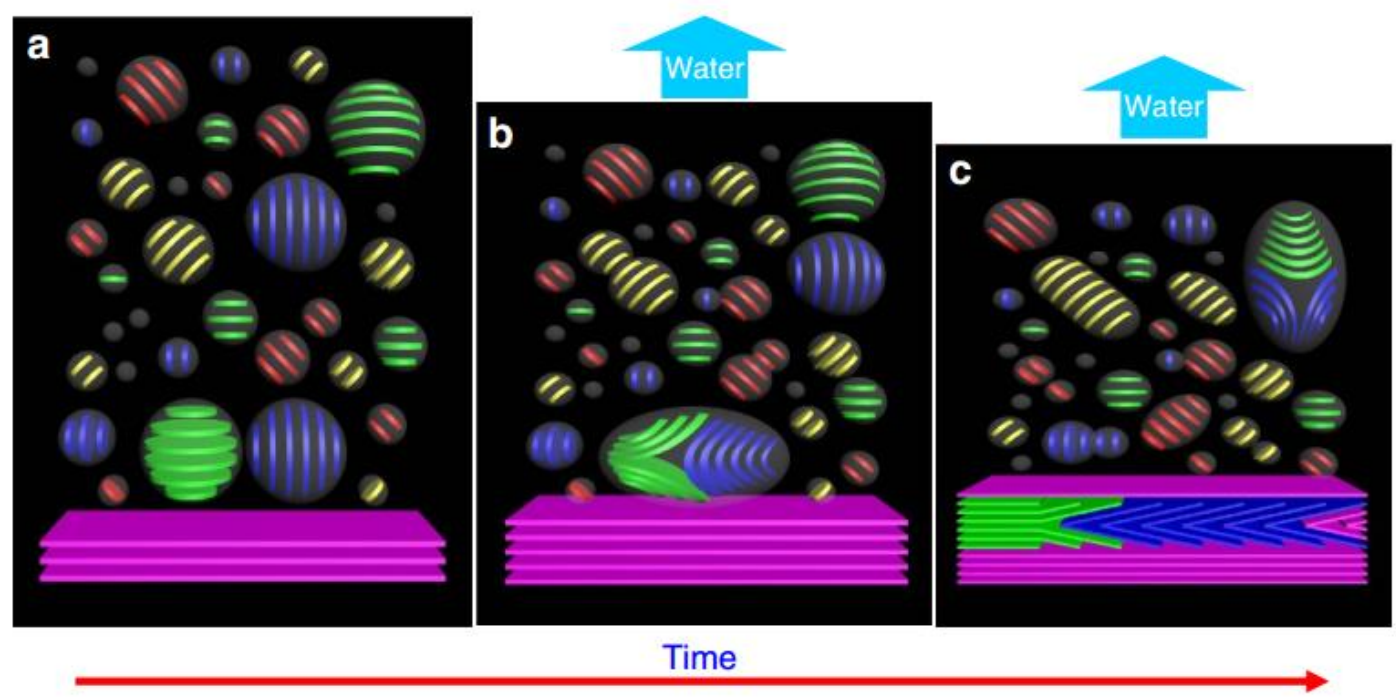

Fig. 6. The structure of tactoids in CNC suspension and its change with solvent evaporation; Reproduced with permission from Nature Communications

Wei et al. (2021). "CNC-based liquid crystals structure," BioResources 16(1), 2116-2137. 2123 
(b)

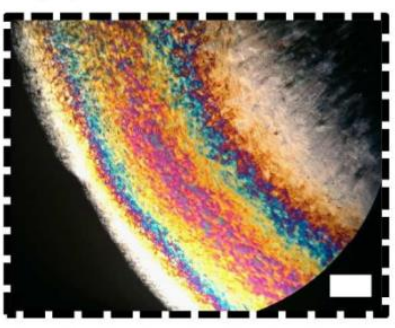

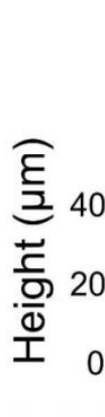

(a)

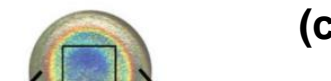

(c)

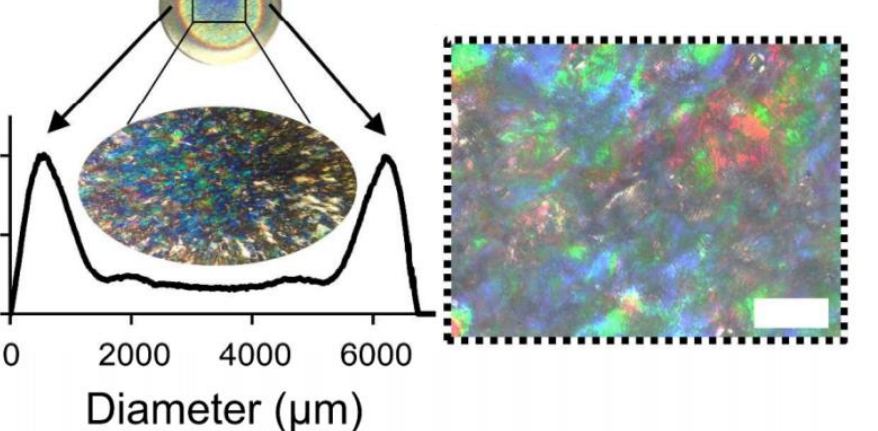

Diameter $(\mu \mathrm{m})$

Fig. 7. The $3.7 \mathrm{wt} \%$ CNC suspension was dried at a relative humidity of $40 \%$ to obtain a film. (a) The color observed by the naked eye and the height profile along its diameter, (b) the edge thickness of the CNC-based LC film under the POM (scale bar $200 \mu \mathrm{m}$ ), and (c) the center of the CNC-based LC film under the POM (scale bar $50 \mu \mathrm{m}$ ); Reproduced with permission from Langmuir https://pubs.acs.org/doi/abs/10.1021/acs.langmuir.6b03724

This phenomenon is due to the fact that the evaporation rate at the edge of the droplet is higher than that at the center, which leads to capillary flow from inside to outside, bringing suspended particles to the edge of the droplet and depositing them in a ring shape at the edge, forming ring-shaped deposits. Consequently, the thickness of the center of the film becomes lower than the edge, and the optical phenomena associated with the corresponding positions are also different (Gençer et al. 2019). From the microscopic level, the change is more obvious. Under POM imaging, at the edge of film there are more obvious bands, and the center shows relatively uniform color. This makes the color of the film inhomogeneous, and it also makes the film have non-uniform optical characteristics.

\section{Controlled Film of CNC-based Liquid Crystals}

To obtain uniform and controlled optical properties of a CNC-based LC film, the effects of a number of parameters such as the concentration of the suspension, electric field, magnetic field, light irradiation, vacuum pressure, and temperature have been studied (Pijpera and Feringa 2008; Wang and Li 2012; Bisoyi and Li 2014, 2016; Wang and Li 2016; Frka-Petesic et al. 2017a, b). The simplest mechanical method to obtain a film with uniform and controlled optical properties is vacuum-assisted self-assembly (VASA). This approach was first used by deHeer et al. (1995). In 2014, Chen and others made more explorations on VASA technology. They reported a high orientation, centimeter grade, and uniform structure of CNC-based LC iridescent films obtained by using VASA technology (Chen et al. 2014). The random distribution of spiral direction resulted in vivid colors of CNC-based LC films. With the most universal evaporationinduced self-assembly (EISA) method, it was different from the uniform color obtained by VASA method. Scanning electron microscope (SEM) images show well-ordered local chiral structure in the cross-sectional images (Wang et al. 2019) (Fig. 8). 
(a)

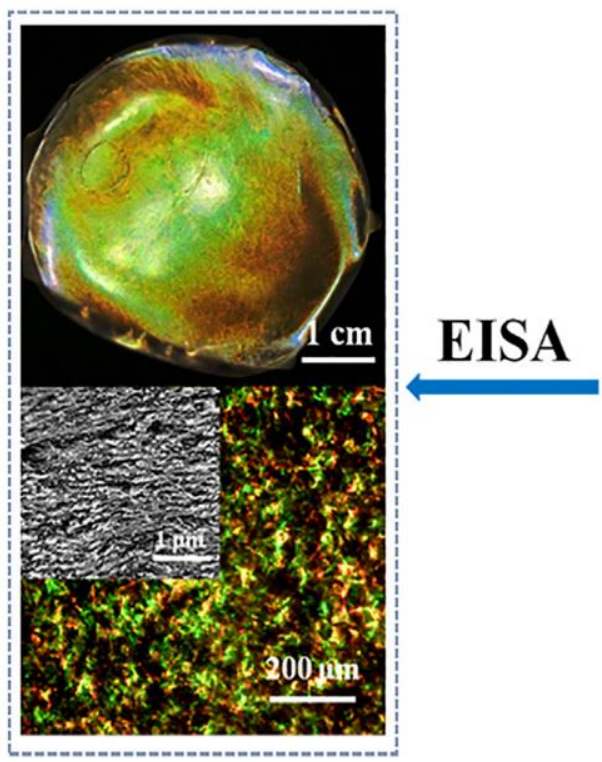

(b)

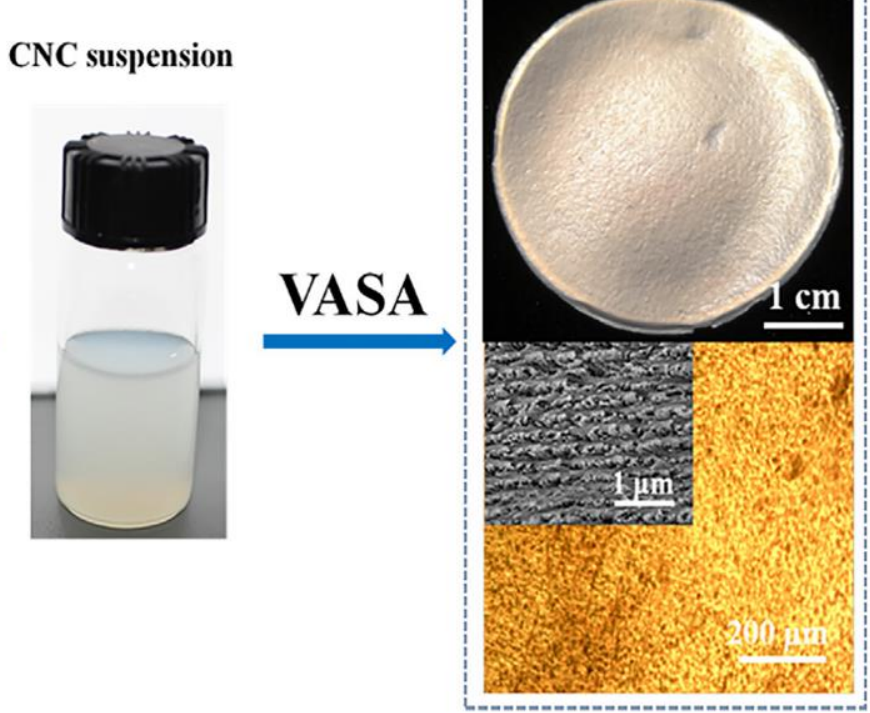

Fig. 8. Digital photographs and POM images of CNC-based LC films prepared by EISA method (a) and VASA method (b). The inset in POM is the cross-sectional SEM picture of the corresponding film; Reproduced with permission from Current Opinion in Solid State \& Materials Science

Park et al. (2014) proposed another mechanical method to solve the nonuniformity problem and promote the orientation of the helical axis perpendicular to the film plane. The first step is to select the initial CNC aqueous suspension with a high concentration to make it completely liquid crystalline, so as to eliminate the internal interfaces at the tactoid boundaries that are peculiar in the phase coexistence regime. Then, circular shear flow is applied in the drying process, which breaks the symmetry and further improves the vertical development of the helical pattern.

Controlling $P$ and chirality (twist) can also improve the uniformity of the film. Beck et al. (2011) found that ultrasonic treatment can control the $P$ of CNC-based LC structure, and the light wavelength of selectively reflecting iridescent film was red shifted. France et al. (2016) studied the kinetics of CNC concentration (1.65 to $8.25 \mathrm{wt} \%$ ) and the degree of $\mathrm{CNC}$ ordering under the condition of weak magnetic field ( 0 to 1.2T). $\mathrm{CNC}$ orientation under relatively weak magnetic field was successfully obtained, and the initial chirality (twist) was accelerated with the increase of magnetic field strength. That was helpful for designing and controlling optical properties of CNC-based LC film. Chen et al. (2020) added $\mathrm{Fe}_{3} \mathrm{O}_{4}$ nanoparticles into $\mathrm{CNC}$ solution and adjusted the value of $P$ by applying an ultra-small magnetic field. Research showed that with the increase of magnetic field strength, the $P$ of CNC-based LC film decreases. By this method, the $P$ can be adjusted and the uniformity of the film can be improved. In addition, Habibi et al. (2008) applied alternating current (AC) electric field to a concentration of $0.5 \%(\mathrm{w} / \mathrm{v})$ $\mathrm{CNC}$ that was dispersed in cyclohexane to make them highly oriented. The results showed that the rod-shaped nanocrystalline particles were parallel to the direction of the electric field after orientation, which is different from the orientation direction in the magnetic field.

Wei et al. (2021). "CNC-based liquid crystals structure," BioResources 16(1), 2116-2137. 2125 

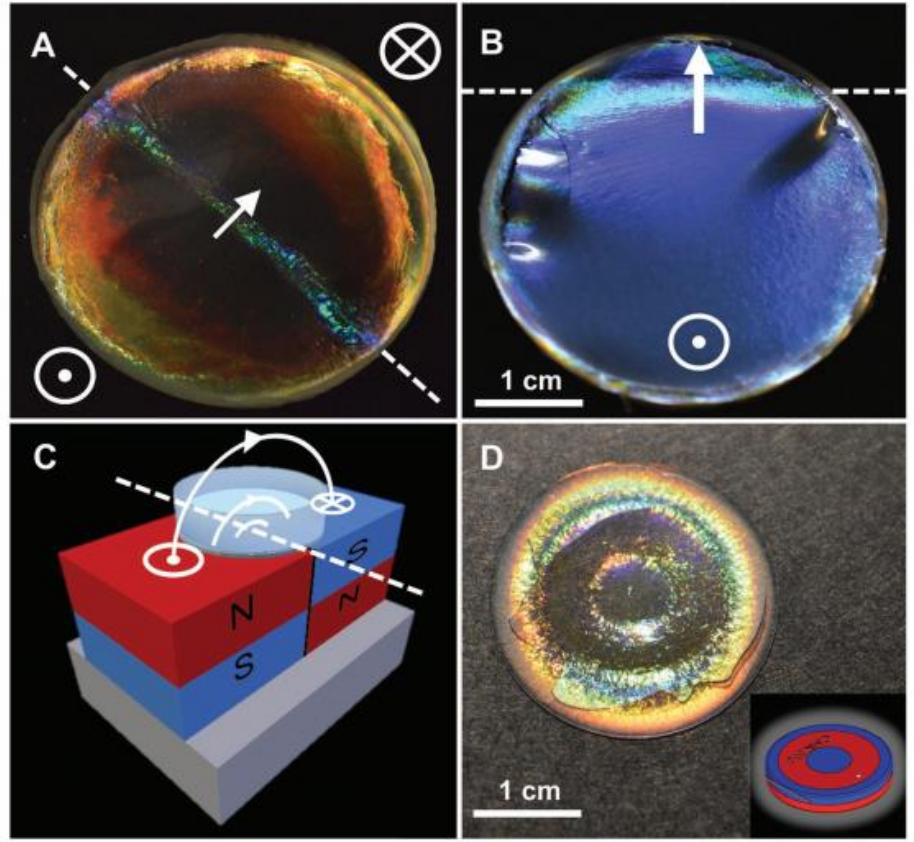

Fig. 9. Examples of films that were cast spanning two magnets (A, B). Corresponding schematic (c). Examples of films that were cast under the patterned polydomain magnet (Polymagnet). The inset shows a schematic of the templating polymagnet (D); Reproduced with permission from Advanced Materials

Frka-Petesic et al. (2017b) used an apolar solvent (toluene) instead of traditional water as the solvent of $\mathrm{CNC}$, and they applied $\mathrm{AC}$ electric fields with different intensity. It was found that this approach not only can adjust the pitch accurately, but it also can achieve the dynamic control of sample uniformity and structure color on macroscale. Then in the same year, they found that by using small and different $\mathrm{NdFeB}$ magnets $(\approx$ 0.5 to $1.2 \mathrm{t}$ ) one can control the $P$ and chirality (twist) direction of CNC suspension cast to films (Bruno Frka-Petesic et al. 2017a). As shown in Fig. 8, the films were all obtained by evaporation of $\mathrm{CNC}$ aqueous suspension in a dish placed on $\mathrm{NdFeB}$ magnet. Figures 9A and $\mathrm{B}$ were obtained with two magnets adjacent to each other. As shown in Fig. $8 \mathrm{~A}$, the adjacent line of two magnets was in the middle of the film, and the adjacent line was on the upper part of the film, whereas Fig. $8 \mathrm{C}$ is the schematic of A and B. Figure 9D indicates that the magnet field exhibited the opposite magnetic poles on the same plane, and the resulting CNC-based LC film appeared exquisitely patterned, as shown in the insert with a corresponding schematic.

In order to further improve the application of CNC-based LC films, in recent years there have been many studies on the control of mechanical properties. Tatsumi et al. (2012) mixed 2-hydroxyethyl methacrylate (HEMA) monomer solution with CNC to obtain a composite colored LC film before initiating polymerization of the monomer, and then proceeded with polymerization to improve the mechanical properties of the composite film. However, the $P$ of the composite CNC-based LC film prepared by this method was too large to reflect the visible spectrum, so that no color can be observed by the naked eye. Zhou (2012) added a certain amount of polyvinyl alcohol (PVOH) or styrene latex (SB-latex) to the $\mathrm{CNC}$ suspension to prepare a flexible and colored CNCbased LC film. The color of the film that contained PVOH was brighter than that of film

Wei et al. (2021). "CNC-based liquid crystals structure," BioResources 16(1), 2116-2137. 2126 
added with polystyrene latex. The addition of styrene latex also will give the CNC-based LC film a higher tensile strength. Bardet et al. (2014) added 10\% polyethylene glycol (PEG) to the mass fraction of 5.3\% CNC suspension to improve the flexibility of the CNC-based LC film and they used anionic polyacrylate (PAAS) to adjust the color of the CNC-based LC film (Fig. 10). In addition, there are some artificially synthesized multihydrogen-bond polymers that have also been tried to increase the flexibility of $\mathrm{CNC}$ based LC films (Zhu et al. 2016).

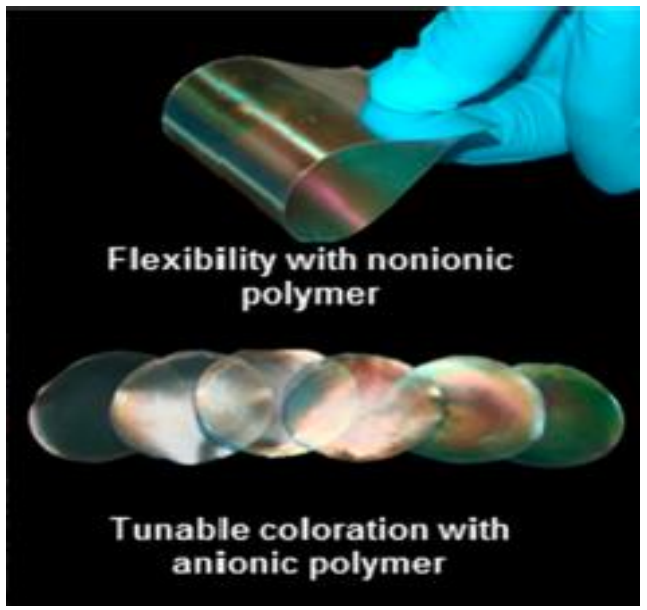

Fig. 10. Flexibility and color change of CNC-based LC film after adding PEG and PAAS; Reprinted with permission from (Bardet et al. 2014). Copyright (2014) American Chemical Society

\section{OPTICAL APPLICATIONS OF CNC-BASED LIQUID CRYSTAL FILMS}

\section{Anti-counterfeiting}

CNC-based LCs possess unique characteristics of structure and optical property in films and this has been widely studied. Under the irradiation of an ultraviolet light source, circular polarizer, naked eye, and chiral spectrometer, the iridescent characteristics of CNC-based LC film can be recognized, which makes the CNC-based LC film have good potential for anti-counterfeiting. Zhang et al. (2012) found that the addition of a fluorescent whitening agent (FWA or OBA) can increase the spacing of CNC-based LC linear structures, at the same time, the iridescent properties of CNC-based LC film will not be affected by its own strong ultraviolet fluorescence at low concentration (Fig. 11). Bardet et al. (2015) provided a particular method to apply CNC-based LC film. Compared with the traditional whole film application, they used effective methods of appropriate grinding and various post-treatments obtained fragmented films with small platelet shape and average thickness of $25 \mu \mathrm{m}$. These structural colors were preserved in fragment film, which made them show strong iridescent color, thus realizing an anticounterfeiting function. Gan et al. (2019) studied a way to form vertical-assembly CNC, and the corresponding film with an anti-counterfeiting pattern could hide its information under natural light when the CNC was shorter than $144 \mathrm{~nm}$ and show the hidden information under UV radiation. 


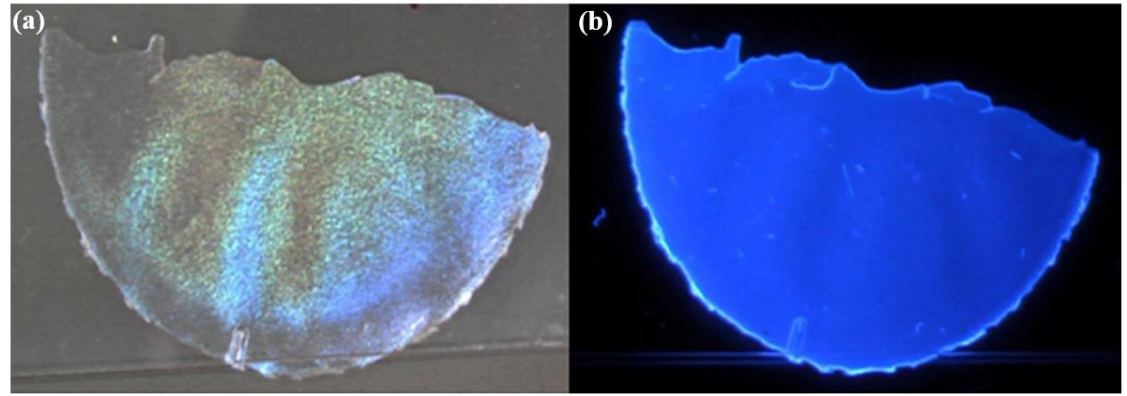

Fig. 11. Iridescent CNC-based LC film doped with 50 ppm TINOPAL OBA (a, under conventional illumination) and excited with UV light (b). Reproduced with permission from Proceedings of SPIE

\section{Colorimetric Sensor}

The stable structural color of CNC-based LC film is sensitive and has unique functions, which will change its color under the stimulation of external conditions. The discoloration of this color can even be observed with the naked eye. This makes it have great prospects in colorimetric sensing. Kelly et al (2013) reported a novel nanocomposite hydrogel with chiral nematic structure and photonic properties, which was prepared from $\mathrm{CNC}$ and various hydrogel monomers. These new hydrogels will exhibit color changes under the external stimulation of solvent, $\mathrm{pH}$, and temperature. Yao et al. (2017) used poly (ethylene glycol) (PEG) and CNC to construct a humidityresponsive photonic material. When the relative humidity was between $50 \%$ and $100 \%$, the $\mathrm{CNC} /$ polyethylene glycol (80/20) composite film showed a reversible and smooth structural color change between green and transparent (Fig. 12). He et al. (2018) successfully prepared CNC composite films responding to humidity and mechanical compression by introducing glycerol as plasticizer. The structure color of the films can be changed by adjusting its chiral nematic structure. When exposed to $16 \%$ to $98 \%$ relative humidity, the film showed reversible color change. In addition, the film can quantitatively sense the compression pressure by exhibiting iridescent color changes. Zhao et al. (2020) showed that CNC-based LC films can have double responses to humidity and formaldehyde gas, and the change of structural color was reversible. Interestingly, compared with the single formaldehyde response, the color transform caused by formaldehyde can be changed from invisible to visible when the film is exposed to a humid environment.

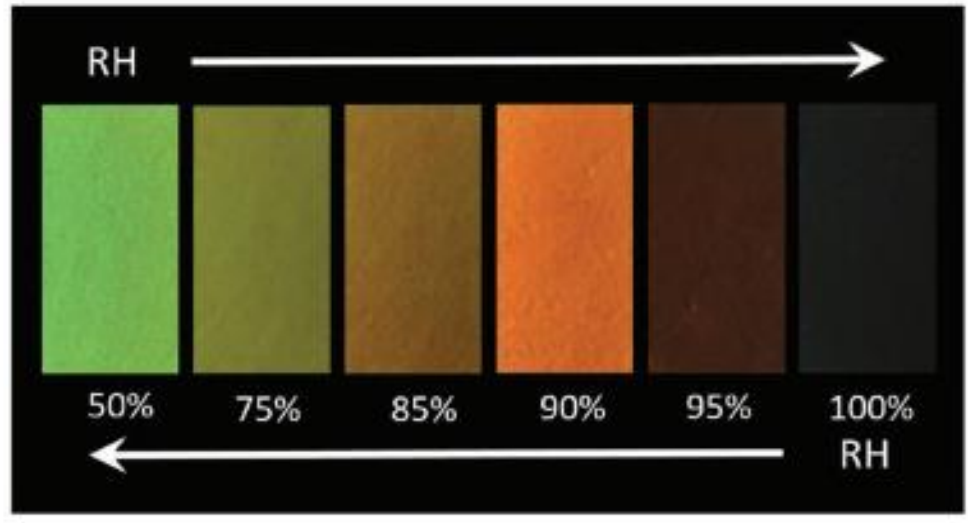

Fig. 12. Reversible structural color change of the CNC-2/PEG (80/20) film under different $R H$. Reproduced with permission from Advanced Materials

Wei et al. (2021). "CNC-based liquid crystals structure," BioResources 16(1), 2116-2137. 2128 


\section{Optical Composite Devices}

The CNC-based LC films can also be applied to a composite device because of its optical characteristics. Cao et al. (2018) added hundreds of sub-micrometric micelles of anionic surfactant into $\mathrm{CNC}$ aqueous suspension to prepare CNC-based LC film. Under the transmission circular dichroism and UV-Vis spectroscopy, the left circularly polarized reflection band of this film is significantly widened. This may be used as a broadband circular polarizer or an optical filter in the future.

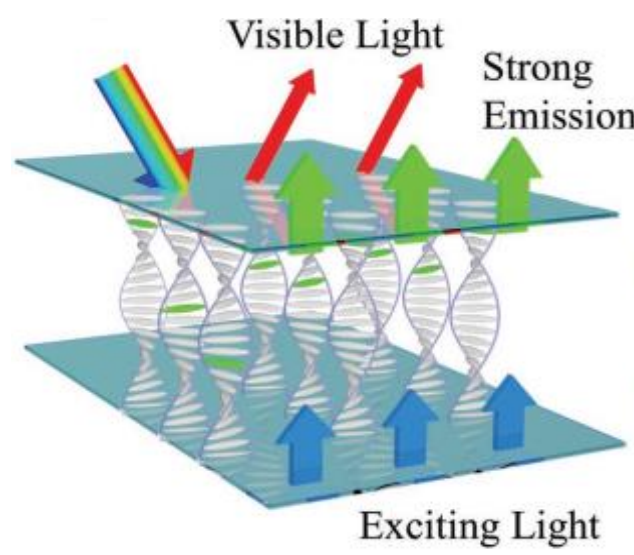

Colored State

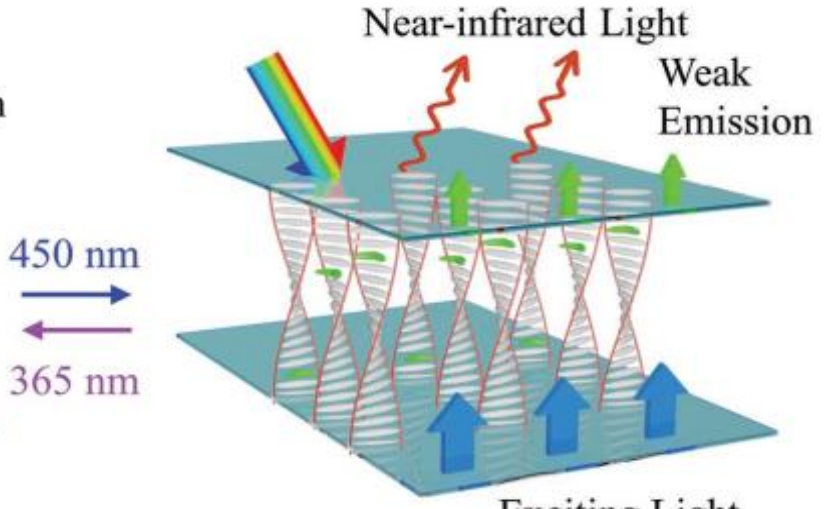

Exciting Light

Fig. 13. Schematics of self-organized helical superstructures in CNC-based LC tuned by visible/UV light for optically rewritable transparent LC displays. Reproduced with permission from Advanced Materials

Grey et al. (2019) reported on CNC-based LC film that was integrated with amorphous indium-gallium-zinc-oxide (a-IGZO) transistors to produce a transistor device. Combining the optical characteristics of CNC with light sensitivity of a-IGZO, the final transistor device can distinguish between left- and right-handed circular polarized light. This approach increased response in the transmission mode. Li et al. (2019) synthesized a photosensitive fluorescent chiral molecule as chiral dopant of cholesteric LC. Under the alternating irradiation of ultraviolet light and blue light, the pitch of LC in the box changed due to the isomerization of photosensitive molecules, which led to the change of the reflection wavelength. This was applied to liquid crystal display devices (Fig. 13).

\section{CLOSING STATEMENTS}

This review has briefly introduced information related to liquid crystals and CNCbased liquid crystals, including molecular units, structural characteristics, and general preparation of CNC. It is necessary to understand what is happening with CNC-based LC aqueous suspensions, including the forming stages and defects of CNC-based liquid crystals, in order to obtain a better CNC-based liquid crystal films. Although there are still some problems in the production of CNC-based liquid crystal films, many ways to control and solve these defects have appeared. Optical applications of CNC LCs in anticounterfeiting, colorimetric sensors, and composite devices have been widely studied. 
Therefore, we believe that the examples discussed in this article will improve the basic understanding of the CNC-based liquid crystals as well as generate interest about optical application of CNC-based liquid crystal films. In addition, CNC-based liquid crystals can be expected to receive more extensive development in the future.

\section{ACKNOWLEDGMENTS}

The authors thank the Natural Science Basic Research Project in Shaanxi Province of China (2018JM2034), Science and Technology Research Project in Xianyang City, Shaanxi Province of China (2017k02-20) for their financial support.

\section{REFERENCES CITED}

Almeida, A. P. C., Canejo, J. P., Fernandes, S. N., Echeverria, C., Almeida, P. L., and Godinho, M. H. (2018). "Cellulose-based biomimetics and their applications," $A d v$. Mater. 30(19), article ID 1703655. DOI: 10.1002/adma.201703655

Amin, K. N. M., Annamalai, P. K., Morrow, I. C., and Martin, D. (2015). "Production of cellulose nanocrystals via a scalable mechanical method," $R S C A d v$. 5, 57133-57140. DOI: 10.1039/C5RA06862B

Bardet, R., Belgacem, N., and Bras, J. (2014). "Flexibility and color monitoring of cellulose nanocrystal iridescent solid films using anionic or neutral polymers," ACS Appl. Mater. Inter. 7(7), 4010-4018. DOI: 10.1021/am506786t

Bardet, R., Roussel, F., Coindeau, S., Belgacem, N., and Bras, J. (2015). "Engineered pigments based on iridescent cellulose nanocrystal films," Carbohyd. Polym. 122, 367-375. DOI: 10.1016/j.carbpol.2014.10.020

Beck-Candanedo, S., Roman, M., and Gray, D. G. (2005). "Effect of reaction conditions on the properties and behavior of wood cellulose nanocrystal suspensions," Biomacromolecules 6(2), 1048-1054. DOI: 10.1021/bm049300p

Beck, S., Bouchard, J., and Berry, R. (2011). "Controlling the reflection wavelength of iridescent solid films of nanocrystalline cellulose," Biomacromolecules 12(1), 167172. DOI: $10.1021 / \mathrm{bm} 1010905$

Bisoyi, H. K., and Li, Q. (2014). "Light-directing chiral liquid crystal nanostructures: From 1D to 3D," Accounts. Chem. Res. 47(10), 3184-3195. DOI: 10.1021/ar500249k

Bondeson, D., Mathew, A., and Oksman, K. (2006). "Optimization of the isolation of nanocrystals from microcrystalline cellulose by acid hydrolysis," Cellulose 13(2), 171-180. DOI: 10.1007/s10570-006-9061-4

Brinchi, L., Cotana, F., Fortunati, E., and Kenny, J. M. (2013). "Production of nanocrystalline cellulose from lignocellulosic biomass: Technology and applications," Carbohyd. Polym. 94(1), 154-169. DOI: 10.1016/j.carbpol.2013.01.033

Cao, X., Ding, B., Yu, J., and Al-Deyab, S. S. (2012). "Cellulose nanowhiskers extracted from TEMPO-oxidized jute fibers,” Carbohydr. Polym. 90, 1075-1080. DOI: 10.1016/j.carbpol.2012.06.046

Cao, Y. Y., Hamad, W. Y., and Maclachlan, M. J. (2018). "Broadband circular polarizing film based on chiral nematic liquid crystals," Adv. Optic. Mater. 6(17), 1800412.11800412.7. DOI: 10.1002/adom.201800412 
Capron, I., Rojas, O. J., and Bordes, R. (2017). "Behavior of nanocelluloses at interfaces," Curr. Opin. Colloid. Interface Sci. 29, 83-95. DOI: 10.1016/j.cocis.2017.04.001

Chen, Q., Liu, P., Nan, F., Zhou, L., and Zhang, J. (2014). "Tuning the iridescence of chiral nematic cellulose nanocrystal films with a vacuum-assisted self-assembly technique," Biomacromolecules 15(11), 4343-4350. DOI: 10.1021/bm501355x

Chen, T., Zhao, Q., Meng, X., Li, Y., Peng, H., Whittaker, A. K., and Zhu, S. (2020) "Ultrasensitive magnetic tuning of optical properties of films of cholesteric cellulose nanocrystals," ACS Nano 14(8), 9440-9448. DOI: 10.1021/acsnano.0c00506

Chen, X., Deng, X., Shen, W., and Jiang, L. (2012). "Controlled enzymolysis preparation of nanocrystalline cellulose from pretreated cotton fibers," BioResources 7(3), 42374248. DOI: 10.15376/biores.7.3.4237-4248

Collings, P. J. (1990). Liquid Crystals: Nature's Delicate Phase of Matter, Princeton University Press, Princeton, NJ, USA.

Collings, P. J. (1998). "Introduction to liquid crystals: Chemistry and physics," Am. J. Phys. 66(6), 551-551. DOI: 10.1119/1.18901

Deegan, R. D., Bakajin, O., Dupont, T. F., Huber, G., Nagel, S. R., and Witten, T. A. (1997). "Capillary flow as the cause of ring stains from dried liquid drops," Nature 389(6653), 827-829. DOI: 10.1038/39827

deHeer, W. A., Bacsa, W. S., Châtelain, A., Gerfin, T., Humphrey-Baker, R., Forro, L., and Ugarte, D. (1995). "Aligned carbon nanotube films: Production and optical and electronic properties," Science 268(5212), 845-847. DOI: 10.1126/science.268.5212.845

Delepierre, G., Eyley, S., Thielemans, W., Weder, C., Cranston, C., and Zoppe, J. O. (2020). "Patience is a virtue: Self-assembly and physico-chemical properties of cellulose nanocrystal allomorphs," Nanoscale 12, 17480-17493. DOI: 10.1039/D0NR04491A

Dumanli, A. G., van der Kooij, H. M., Kamita, G., Reisner, E., Baumberg, J. J., Steiner, U., and Vignolini, S. (2014). "Digital color in cellulose nanocrystal films," ACS Appl. Mater. Inter. 6(15), 12302-12306. DOI: 10.1021/am501995e

Edgar, C. D., and Gray, D. G. (2011). "Induced circular dichroism of chiral nematic cellulose films," Cellulose 8(1), 5-12. DOI: 10.1023/A:1016624330458

Eichhorn, S. J., Dufresne, A., Aranguren, M., Marcovich, N. E., Capadona, J. R., Rowan, S. J., Weder, C., Thielemans, W., Roman, M., Renneckar, S., et al. (2010). "Review: Current international research into cellulose nanofibres and nanocompositess," $J$. Mater. Sci. 45(1), 1-33. DOI: 10.1007/s10853-009-3874-0

Espinosa, S. C., Kuhnt, T., and Foster, E. J. (2013). "Isolation of thermally stable cellulose nanocrystals by phosphoric acid hydrolysis," Biomacromolecules 14(4), 1223-1230. DOI: 10.1021/bm400219u

Favier, V., Canova, G. R., Cavaille, J. Y., Chanzy, H., Dufresne, A., and Gauthier, C. (1995). "Nanocomposite materials from latex and cellulose whiskers," Polym. Advan. Technol. 6(5), 351-355. DOI: 10.1002/pat.1995.220060514

Flauzino Neto, W. P., Putaux, J. L., Mariano, M., Ogawa, Y., Otaguro, H., Pasquini, D., and Dufresne, A. (2016). "Comprehensive morphological and structural investigation of cellulose I and II nanocrystals prepared by sulphuric acid hydrolysis," $R S C A d v$. 6, 76017-76027. DOI: 10.1039/C6RA16295A 
France, K. J. D., Yager, K. G., Hoare, T., and Cranston, E. D. (2016). "Cooperative ordering and kinetics of cellulose nanocrystal alignment in a magnetic field," Langmuir 32(30), 7564-7571. DOI:10.1021/acs.langmuir.6b01827

Frka-Petesic, B., Guidetti, G., Kamita, G., and Vignolini, S. (2017a). "Controlling the photonic properties of cholesteric cellulose nanocrystal films with magnets," $A d v$. Mater. 29(32), Article ID 1701469. DOI: 10.17863/CAM.12529

Frka-Petesic, B., Radavidson, H., Jean, B., and Heux, L. (2017b). “Dynamically controlled iridescence of cholesteric cellulose nanocrystal suspensions using electric fields," Adv. Mater. 29(11), 1606208. DOI: 10.1002/adma.201606208

Frka-Petesic, B., Kamita, G., Guidetti, G., and Vignolini, S. (2019). “Angular optical response of cellulose nanocrystal films explained by the distortion of the arrested suspension upon drying," Phys. Rev. Mater. 3(4). DOI:

10.1103/PhysRevMaterials.3.045601

Gan, L., Feng, N., Liu, S., Zheng, S., Li, Z., and Huang, J. (2019). “Assembly-induced emission of cellulose nanocrystals for hiding information," Part. Part. Syst. Charact. 36(3), Article ID 1800412. DOI: 10.1002/ppsc.201800412

Gençer, A., Schütz, C., and Thielemans, W. (2016). "Influence of the particle concentration and marangoni flow on the formation of cellulose nanocrystal films," Langmuir 33(1), 228-234. DOI: 10.1021/acs.langmuir.6b03724

Giese, M., Blusch, L. K., Khan, M. K., and MacLachlan, M. J. (2015). "Functional materials from cellulose-derived liquid-crystal templates," Angew. Chem. Int. Edit. 54(10), 2888-2910. DOI: 10.1002/anie.201407141

Gilbert, R. D. (1994). Cellulosic Polymers, Blends and Composites, Hanser, Munich, Germany.

Gong, J., Li, J., Xu, J., Xiang, Z., and Mo, L. (2017) "Research on cellulose nanocrystals produced from cellulose sources with various polymorphs," RSC Adv. 7(53), 3348633493. DOI: 10.1039/C7RA06222B

Gong, J., Mo, L., and Li, J. (2018). "A comparative study on the preparation and characterization of cellulose nanocrystals with various polymorphs," Carbohyd. Polym. 195, 18-28. DOI: 10.1016/j.carbpol.2018.04.039

Gonzalez-Dominguez, J. M., Ansón-Casaos, A., Grasa, L., Abenia, L., Salvador, A.,Colom, E., Mesonero, J. E., García-Bordejé, J. E., Benito, A. M., and Maser, W. K. (2019). "Unique properties and behavior of nonmercerized type-II cellulose nanocrystals as carbon nanotube biocompatible dispersants," Biomacromolecules 20(8), 3147-3160. DOI: 10.1021/acs.biomac.9b00722

Gray, D. G. (2016). "Recent advances in chiral nematic structure and iridescent color of cellulose nanocrystal films," Nanomaterials-Basel 6(11), article no. 213. DOI: 10.3390/nano6110213

Grey, P., Fernandes, S. N., Gaspar, D., Fortunato, E., Martins, R., Godinho, M. H., and Pereira, L. (2019). "Field-effect transistors on photonic cellulose nanocrystal solid electrolyte for circular polarized light sensing," Adv. Funct. Mater. 29(21), 1805279.1-1805279.8. DOI: 10.1002/adfm.201970145

Grunert, M., and Winter, W. T. (2002). "Nanocomposites of cellulose acetate butyrate reinforced with cellulose nanocrystals," J. Polym. Environ. 10(1/2), 27-30. DOI: 10.1023/A:1021065905986

Habibi, Y., Heim, T., and Douillard, R. (2008). "AC electric field-assisted assembly and alignment of cellulose nanocrystals,” J. Polym. Sci. Pol. Phys. 46(14), 1430-1436.

DOI: $10.1002 /$ polb.21479 
Habibi, Y., Lucia, L. A., and Rojas, O. J. (2010). "Cellulose nanocrystals: Chemistry, self-assembly, and applications," Chem. Rev. 110(6), 3479-3500. DOI: $10.1021 / \mathrm{cr} 900339 \mathrm{w}$

He, Y., Zhang, Z., Xue, J., Wang, X. H., Song, F., Wang, L. X., and Zhu L. (2018). "Biomimetic optical cellulose nanocrystal films with controllable iridescent color and environmental stimuli-responsive chromism," ACS Appl. Mater. Inter. 10(6), 58055811. DOI: 10.1021/acsami.7b18440

Hiraia, A., Inui, O., Horii, F., and Tsuji, M. (2009). "Phase separation behavior in aqueous suspensions of bacterial cellulose nanocrystals prepared by sulfuric acid treatment," Langmuir 25(1), 497-502. DOI: 10.1021/la802947m

Huang, W., Restrepo, D., Jung, J. Y., Frances, Y. S., Zeng, L., Ritchie, R. O., McKittrick, J., Zavattieri, P., and Kisailus, D. (2019). "Multiscale toughening mechanisms in biological materials and bioinspired designs," Adv. Mater. 31(43), e1901561. DOI: 10.1002/adma.201901561

Ingo, D., and Shakhawan, A. Z. (2017). "Lyotropic liquid crystal phases from anisotropic nanomaterials," Nanomaterials 7(10), Article Number 305. DOI: 10.3390/nano7100305

Ishikawa, A., Okano, T., and Sugiyama, J. (1997). "Fine structure and tensile properties of ramie fibres in the crystalline form of cellulose I, II, Ill, and IV $\mathrm{I}_{\mathrm{I}}$," Polymer 38, 463-468. DOI: 10.1016/S0032-3861(96)00516-2

Jonoobi, M., Oladi, R., Davoudpour, Y., Oksman, K., Dufresne, A., Hamzeh, Y., and Davoodi, R. (2015). "Different preparation methods and properties of nanostructured cellulose from various natural resources and residues: A review," Cellulose 22, 935969. DOI: 10.1007/s10570-015-0551-0

Kelly, J. A., Giese, M., Shopsowitz, K. E., Hamad, W. Y., and MacLachlan, M. J. (2014). "The development of chiral nematic mesoporous materials," Accounts. Chem. Res. 47(4), 1088-1096. DOI: 10.1021/ar400243m

Kelly, J. A., Shukaliak, A. M., Cheung, C. C. Y., Shopsowitz, K. E., Hamad, W. Y., and MacLachlan, M. J. (2013). "Responsive photonic hydrogels based on nanocrystalline cellulose," Angew. Chem. Int. Edit. 52(34), 8912-8916. DOI:

10.1002/anie.201302687

Kitzerow, H., and Bahr, C. (2001). "Chirality in liquid crystals," J. Mater. Chem. 1(3), 307-318. DOI: $10.1007 / \mathrm{b} 97374$

Klemm, D., Cranston, E. D., Fischer, D., Gama, M., Kedzior, S. A., Kralisch, D., Kramer, F., Kondo, T., Lindström, T., Nietzsche, S., et al. (2018). "Nanocellulose as a natural source for groundbreaking applications in materials science: Today's state," Mater. Today 21(7), 720-748. DOI: 10.1016/j.mattod.2018.02.001

Klemm, D., Kramer, F., Moritz, S., Lindström, T., Ankerfors, M., Gray, D., and Dorris, A. (2011). "Nanocelluloses: A new family of nature-based materials," Angew. Chem. Int. Edit. 50(24), 5438-5466. DOI: 10.1002/anie.201001273

Kuang, Y., Li, X., Luan, P., Zhang, X., Xu, J., Mo, L., Gong, J., and Li, J. (2020). "Cellulose II nanocrystal: A promising bio-template for porous or hollow nano SiO2 fabrication," Cellulose 27, 3167-3179. DOI: 10.1007/s10570-020-02973-6

Lagerwall, S. T. (2013). "On some important chapters in the history of liquid crystals," Liq. Cryst. 40(12), 1698-1729. DOI: 10.1080/02678292.2013.831134

Laitinen, O., Ojala, J., Sirviö, J. A., and Liimatainen, H. (2017). "Sustainable stabilization of oil in water emulsions by cellulose nanocrystals synthesized from deep eutectic solvents," Cellulose 24(4), 1679-1689. DOI:10.1007/s10570-017-1226-9

Wei et al. (2021). "CNC-based liquid crystals structure," BioResources 16(1), 2116-2137. 2133 
Levin, D., Saem, S., Osorio, D. A., Cerf, A., Cranston, E. D., and Moran-Mirabal, J. M. (2018). "Green templating of ultraporous cross-linked cellulose nanocrystal microparticles," Chem. Mater. 30(21), 8040-8051. DOI: 10.1021/acs.chemmater.8b03858

Li, J., Bisoyi, H. K., Tian, J., Guo, J., and Li, Q. (2019). “Optically rewritable transparent liquid crystal displays enabled by light - driven chiral fluorescent molecular switches," Adv. Mater. 31(10), 1807751.1-1807751.7. DOI: 10.1002/adma.201807751

Lima, M. M. S., and Borsali, R. (2004). "Rodlike cellulose microcrystals: Structure, properties, and applications," Macromol. Rapid Comm. 25(7), 771-787. DOI: 10.1002/marc.200300268

Ling, S., Kaplan, D. L., and Buehler, M. J. (2018). "Nanofibrils in nature and materials engineering," Nature Reviews Materials 3(4), Article Number 18016. DOI: 10.1038/natrevmats.2018.16

Liu, Q., Campbell, M. G., Evans, J. S., and Smalyukh, I. I. (2014). “Orientationally ordered colloidal co-dispersions of gold nanorods and cellulose nanocrystals," $A d v$. Mater. 26(42), 7178-7184. DOI: 10.1002/adma.201402699

Li, Y., Wang, M., White, T. J., Bunning, T. J., and Li, Q. (2013a). “Azoarenes with opposite chiral configurations: Light-driven reversible handedness inversion in selforganized helical superstructures," Angew. Chem. Int. Edit. 125(34), 9093-9097. DOI: 10.1002/ange.201303786

Li, Y., Xue, C., Wang, M., Urbas, A., and Li, Q. (2013b). "Photodynamic chiral molecular switches with thermal stability: From reflection wavelength tuning to handedness inversion of self-organized helical superstructures," Angew. Chem. Int. Edit. 52(51), 13703-13707. DOI: 10.1002/anie.201306396

Mao, J., Osorio-Madrazo, A., and Laborie, M. P. (2013). "Preparation of cellulose I nanowhiskers with a mildly acidic aqueous ionic liquid: Reaction efficiency and whiskers attributes," Cellulose 20(4), 1829-1840. DOI: 10.1007/s10570-013-9942-2

Mathews, M., Zola, R. S., Hurley, S., Yang, D. K., White, T. J., Bunning, T. J., and Li, Q. (2010). "Light-driven reversible handedness inversion in self-organized helical superstructures," J. Am. Chem. Soc. 132(51), 18361-18366. DOI: 10.1021/ja108437n

Mitov, M. (2017). "Cholesteric liquid crystals in living matter," Soft Mater. 13(23), 41764209. DOI: $10.1039 / \mathrm{c} 7 \mathrm{sm} 00384 \mathrm{f}$

Moon, R. J., Martini, A., Nairn, J., Simonsen, J., and Youngblood, J. (2011). "Cellulose nanomaterials review: Structure, properties and nanocomposites," Chem. Soc. Rev. 40(7), 3941- 3994. DOI: 10.1039/c0cs00108b

Nguyen, T. D., Sierra, E., Eguiraun, H., Lizundia, E. (2018). "Iridescent cellulose nanocrystal films: The link between structural colour and Braggs law," Eur. J. Phys. 39(4), 045843. DOI: 10.1088/1361-6404/aab598

Nishio, Y., Sato, J., and Sugimura, K. (2016). "Cellulose chemistry and properties: Fibers, nanocelluloses and advanced materials," in: Fascinating Ordered Structures for the Design of Functional Material Systems, Springer International Publishing, Cham, Switzerland, pp. 241-286.

Okura, H., Wada, M., and Serizawa, T. (2014). "Dispersibility of HCl-treated cellulose nanocrystals with water-dispersible properties in organic solvents," Chem. Lett. 43(5), 601-603. DOI: 10.1246/cl.131181 
Oswald, P., and Pieranski, P. (2005). Nematic and Cholesteric Liquid Crystals: Concepts and Physical Properties Illustrated by Experiments, Taylor \& Francis, Boca Raton, FL, USA.

Parker, R. M., Guidetti, G., Williams, C. A., Zhao, T. H., Narkevicius, A., Vignolini, S., and Frka-Petesic, B. (2018). "The self-assembly of cellulose nanocrystals: Hierarchical design of visual appearance," Adv. Mater. 30(19), Article ID e1704477. DOI: 10.1002/adma.201704477

Park, J. H., Noh, J., Schütz, C., Salazar-Alvarez, G., Scalia, G., Bergström, L., and Lagerwall, J. P. F. (2014). "Macroscopic control of helix orientation in films dried from cholesteric liquid-crystalline cellulose nanocrystal suspensions," Chemphyschem 15(7), 1477-1484. DOI: 10.1002/cphc.201400062

Passantino, J. M., Haywood, A. D., Goswami, J. and Davis, V. A. (2017). "Effects of polymer additives and dispersion state on the mechanical properties of cellulose nanocrystal films," Macromol. Mater. Eng. 302(4), 1600351. DOI: 10.1002/mame.201600351

Pijpera, D., and Feringa, B. L. (2008). "Control of dynamic helicity at the macro- and supramolecular level," Soft Matter 4(7) 1349-1372. DOI: 10.1039/B801886C

Podsiadlo, P., Choi, S. Y., Shim, B., Lee, J., Cuddihy, M., and Kotov, N. A. (2005). "Molecularly engineered nanocomposites: Layer-by-layer assembly of cellulose nanocrystals," Biomacromolecules 6(6), 2914-2918. DOI: 10.1021/bm050333u

Qin, Z.-Y., Tong, G., Chin Y. F. and Zhou, J.-C. (2011). "Preparation of ultrasonicassisted high carboxylate content cellulose nanocrystals by TEMPO oxidation," BioResources 6, 1136-1146. DOI: 10.15376/biores.6.2.1136-1146

Revol, J. F., Bradford, H., Giasson, J., Marchessault, R. H., and Gray, D. G. (1992). "Helicoidal self-ordering of cellulose microfibrils in aqueous suspension," Int. J. Biol. Macromol. 14(3), 170-172. DOI: 10.1016/S0141-8130(05)80008-X

Revol, J. F., Godbout, L., and Gray, D. G. (1998). "Solid self-assembled films of cellulose with chiral nematic order and optically variable properties," J. Pulp. Pap. Sci. 24(5), 146-149.

Revol, J. F., Godbout, L., Dong, X. M., Gray, D. G., Chanzy, H., and Maret, G. (1994). "Chiral nematic suspensions of cellulose crystallites; phase separation and magnetic field orientation," Liq. Cryst. 16(1), 127-134. DOI: 10.1080/02678299408036525

Saito, T., and Isogai, A. (2006). "Introduction of aldehyde groups on surfaces of native cellulose fibers by TEMPO-mediated oxidation," Colloids Surf. A. 289(1-3), 219-225. DOI: 10.1016/j.colsurfa.2006.04.038

Samir, M. A. S. A., Alloin, F., Sanchez, J. Y., and Dufresne, A. (2004a). "Cross-linked nanocomposite polymer electrolytes reinforced with cellulose whiskers," Macromolecules 37(13), 4839-4844. DOI: 10.1021/ma049504y

Samir, M. A. S. A., Alloin, F., Sanchez, J. Y., Kissi, N., and Dufresne, A. (2004b). "Preparation of cellulose whiskers reinforced nanocomposites from an organic medium suspension," Macromolecules 37(4), 1386-1393. DOI: 10.1021/ma030532a

Satyamurthy, P., Jain, P., Balasubramanya, R.H., and Vigneshwaran, N. (2011). "Preparation and characterization of cellulose nanowhiskers from cotton fibres by controlled microbial hydrolysis," Carbohyd. Polym. 83(1):122-129. DOI: 10.1016/j.carbpol.2010.07.029

Schütz, C., Bruckner, J. R., Honorato-Rios, C., Tosheva, Z., Anyfantakis, M., and Lagerwall, J. P. F. (2020). "From equilibrium liquid crystal formation and kinetic 
arrest to photonic bandgap films using suspensions of cellulose nanocrystals," Crystals 10(3), article ID 199. DOI: 10.3390/cryst10030199

Sèbe, G., Ham-Pichavant, F., Ibarboure, E., Koffi, A. L. C., and Tingaut, P. (2012) "Supramolecular structure characterization of cellulose II nanowhiskers produced by acid hydrolysis of cellulose I substrates," Biomacromolecules 13(2):570-578. DOI: $10.1021 / \mathrm{bm} 201777 \mathrm{j}$

Singh, K. B., Bhosale, L. R., and Tirumkudulu, M. S. (2009). "Cracking in drying colloidal films of flocculated dispersions," Langmuir 25(8), 4284-4287. DOI: $10.1021 / 1 \mathrm{a} 804331 \mathrm{c}$

Singla, R., Guliani, A., Kumari, A., and Yadav, S. K. (2016). "Nanocellulose and nanocomposites," in: Nanoscale Materials in Targeted Drug Delivery, Theragnosis and Tissue Regeneration, S. Yadav (ed.), Springer, Singapore, pp. 103-125.

Sirviö, J. A., Visanko, M., and Liimatainen, H. (2016). "Acidic deep eutectic solvents as hydrolytic media for cellulose nanocrystal production," Biomacromolecules 17(9), 3025-3032. DOI: 10.1021/acs.biomac.6b00910

Sonin, A. S. (1998). "Inorganic lyotropic liquid crystals," J. Mater. Chem. 8(12), 25572574. DOI: 10.1039/A802666A

Takezoe, H., and Eremin, A. (2017). Bent-shaped Liquid Crystals: Structures and Physical Properties, CRC Press, Boca Raton, FL, USA.

Tatsumi, M., Teramoto, Y., and Nishio, Y. (2012). "Polymer composites reinforced by locking-in a liquid-crystalline assembly of cellulose nanocrystallites," Biomacromolecules 13(5), 1584-1591. DOI: 10.1021/bm300310f

Tjipto-Margo, B., and Evans, G. T. (1991). "The Onsager theory of the isotropic-nematic -liquidcrystal transition: Biaxial particles in uniaxial phases," J. Chem. Phys. 94(6), 4546-4556. DOI: 10.1063/1.460609

Trache, D., Hussin, M. H., Haafiz, M. K. M., and Thakur, V. K. (2017). "Recent progress in cellulose nanocrystals: sources and production," Nanoscale 9(5), 1763-1786. DOI: 10.1039/c6nr09494e

Tran, A., Boott, C. E., and Maclachlan, M. J. (2020). "Understanding the self-assembly of cellulose nanocrystals - toward chiral photonic materials," Adv. Mater. 32(41). DOI: 10.1002/adma.201905876

Viet, D., Beck-Candanedo, S., and Gray, D. G. (2007). "Dispersion of cellulose nanocrystals in polar organic solvents," Cellulose 14(2), 109-113. DOI: 10.1007/s10570-006-9093-9

Vignolini, S., Rudall, P. J., Rowland, A. V., Reed, A., Moyroud, E., Faden, R. B., Baumberg, J. J., and Glover, B. J. (2012). "Pointillist structural color in Pollia fruit," P. Natl. Acad. Sci. USA. 109(39), 15712-15715. DOI: 10.1073/pnas.1210105109

Vries, H. D. (1951). "Rotary power and other optical properties of certain liquid crystals," Acta Crystallogr. 4(3), 219-226. DOI: 10.1107/s0365110x51000751

Wang, L., and Li, Q. (2012). "Light-driven chiral molecular switches or motors in liquid crystals," Adv. Mater. 24(15), 1926-1945. DOI: 10.1002/adma.201200241

Wang, L., and Li, Q. (2016). "Stimuli-directing self-organized 3d liquid-crystalline nanostructures: From materials design to photonic applications," Adv. Funct. Mater. 26(1), 10-28. DOI: 10.1002/adfm.201502071

Wang, P. X., Hamad, W. Y., and Maclachlan, M. J. (2016). "Structure and transformation of tactoids in cellulose nanocrystal suspensions," Nat. Commun. 7(1), 11515. DOI: 10.1038/ncomms 11515 
Wang, Z., Li, N., Lu, Z., and Zhang, J. (2019). "Recent advances in vacuum assisted selfassembly of cellulose nanocrystals," Current Opinion in Solid State \& Materials Science 23(3), 142-148. DOI:10.1016/j.cossms.2019.03.001.

Werbowyj, R. S., and Gray, D. G. (1984). "Optical properties of hydroxypropyl cellulose liquid crystals. I. Cholesteric pitch and polymer concentration," Macromolecules 17(8), 1512. DOI: 10.1021/ma00138a016

Wu, Q., Xu, J., Wu, Z., Zhu, S., Gao, Y., and Shi, C. (2020). "The effect of surface modification on chemical and crystalline structure of the cellulose III nanocrystals," Carbohyd. Polym. 235, 115962. DOI: 10.1016/j.carbpol.2020.115962

Yao, K., Meng, Q., Bulone, V., and Zhou, Q. (2017). "Flexible and responsive chiral nematic cellulose nanocrystal/poly(ethylene glycol) composite films with uniform and tunable structural color," Adv. Mater. 29(28), 1701323 DOI: 10.1002/adma.201701323

Zhang, Y., Cheng, Q., and Chang, C. (2017). "Phase transition identification of cellulose nanocrystal suspensions derived from various raw materials," J. Appl. Polym. Sci. 135(24), Article ID 45702. DOI: 10.1002/app.45702

Zhang, Y., Chodavarapu, V., Kirk, A., and Andrews, M. (2012). "Nanocrystalline cellulose for covert optical encryption," P. Soc. Photo-Opt. Ins. 6(1), 063516-063526. DOI: 10.1117/ 1.JNP.6.063516

Zhao, G., Zhang, Y., Zhai, S., Sugiyama, J., Pan, M., Shi, J., and Lu, H. (2020). "Dual response of photonic film with chiral nematic cellulose nanocrystal: Humidity and formaldehyde," ACS Appl. Mater. Inter. 12(15), 17833-17844. DOI: 10.1021/ac sami.0c00591

Zheng, Z., Yuan, C., Hu, W., Bisoyi, H. K., Tang, M., Liu, Z., Sun, P., Yang, W., Wang, X., Shen, D., et al. (2017). "Light-patterned crystallographic direction of a selforganized 3D soft photonic crystal," Adv. Mater. 29(42), article ID 1703165. DOI: 10.1002/adma.201703165

Zocher, H., and Jacobsohn, K. (1929). “Über Taktosole,” Kolloidchem. Beih. 28, 167206. DOI: $10.1007 / \mathrm{BF} 02556733$

Zhong, L., Fu, S., Peng, X., Zhan, H., and Sun, R. (2012). "Colloidal stability of negatively charged cellulose nanocrystalline in aqueous systems," Carbohyd. Polym. 90(1), 644-649. DOI: 10.1016/j.carbpol.2012.05.091

Zhou, Q., and Wang, X. J. (1994). Liquid Crystal Polymer, Science Press, Beijing, China. Zhou, X. J. (2012). "Flexible, iridescent nanocrystalline cellulose film, and method for preparation: China," China Patent No. CN102449052 [P]. 2012-05-09.

Zhu, B., Merindol, R., Benitez, A. J., Wang, B., and Walther, A. (2016). "Supramolecular engineering of hierarchically self-assembled, bioinspired, cholesteric nanocomposites formed by cellulose nanocrystals and polymers," ACS Appl. Mater. Inter. 8(17), 11031-11040. DOI: 10.1021/acsami.6b00410

Article submitted: September 22, 2020; Peer review completed: November 21, 2020; Revised version received and accepted: December 16, 2020; Published: January 4, 2021. DOI: 10.15376/biores.16.1.Wei 